of news to try to define what sort of role they might play for citizens: political, world, economic, celebrity, disaster and consumer. He counsels people to master the art of being 'patient midwives to our own thoughts' instead of allowing ourselves to be assailed on all fronts by news. 'We need relief from the news-fuelled impression that we are living in an age of unparalleled importance, with our wars, our debts, our riots, our missing children, our after-premiere parties, our IPOs and our rogue missiles (p. 255). This is a book every journalist, educator and citizen should read. It is not a pessimistic book, it is very clever and eminently readable one.

\section{Lost in translation}

Understanding Micronesia: A cultural guide for researchers and visitors, by Tim Hogan. Penang, Malaysia: Southbound Press. Communication for Development and Social Change Series. 2008. 98 pp. ISBN 9789389054491.

$\mathrm{N}$

EW ZEALAND media and journalists largely equate the 'Pacific' with Polynesia. The focus of reportage and understanding the region begins with the Cook islands and ends with Niue, Samoa and Tonga, with a limited grasp of Fiji.

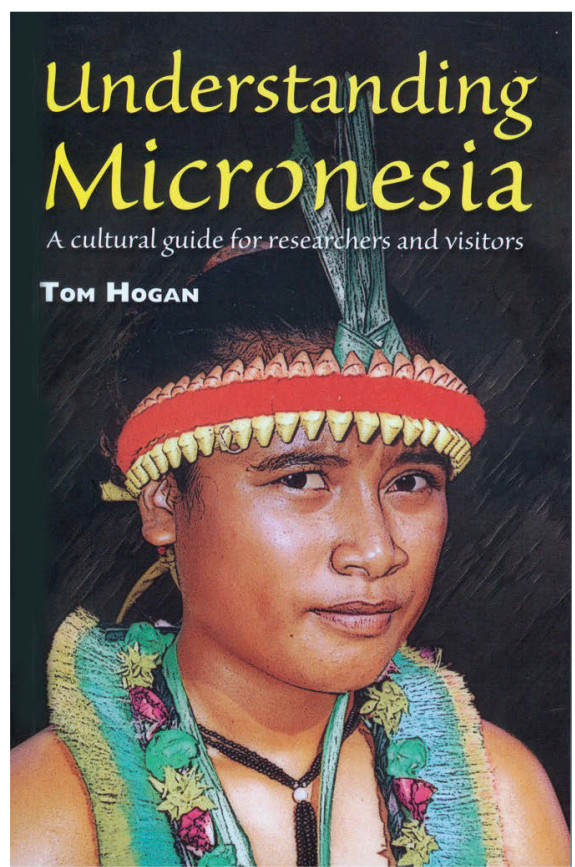

Anything west of Nadi, the Melanesian nations, gains cursory attention and Tahiti Nui (Polynesian) and Kanaky (Melanesian) are all but ignored.

The same goes with Micronesia. This vast region is perceived as an American sphere of interest and so gets little attention, even though three nations from the region, Federated States of Micronesia, Kiribati and the Marshall Islands are members of the Pacific Islands Forum.

There is a tendency for journalists to have simplistic approach to reporting a region, lumping all Pacific cultures and traditions together. In 
reality, the cultures are all complex and unique.

In spite of a 50-year secret agenda of the United States to absorb the United Nations Trust Territory into part of the US developed by the controversial Solomon Report in 1963, Micronesian island states have mainly retained their identity and independence.

Professor Tom Hogan, a former University of Queensland journalism educator and radio broadcaster and producer has written this handy cultural guide, Understanding Micronesia, primarily about the FSM but equally useful for Belau/Palau and the Marshall Islands.

It draws on much of his experience as a radio producer and trainer in the Pacific as part of his career as a consultant for governments in 41 countries in South-east Asia, the Pacific and Australia.

It's a lack of understanding of cultural differences that leads so many wellintentioned visitors to the Micronesian Islands to so much frustration. There is, after all, quite a difference between agreement with and mere acknowledgement of a point of view or suggested course of action. It's not the Micronesian way to disagree (p. 71 [author's emphasis])

Due to misunderstandings, sometimes 'deep and abiding tensions' grow between expatriates and the indigenous people.

Although English is a national language, often radio broadcasters have a rudimentary command of the tongue, not really truly bilingual.

A controversial radio programme was made by Micronesian students in Washington in late 1986 which first exposed on air major socio-cultural differences between Micronesian and Western value systems.

According to a Micronesian broadcaster cited by Hogan, there are advantages in 'dependent bilingualism':

When I speak English, I think first in Yapese and then find the right word in English. There are often ideas which have to be treated very carefully. Like, if I want to say: 'I love my sister,' that's okay in English, but I could be kicked out of my village for saying it like that in Yapese. (p. 56)

\section{—Dr David Robie}

